RESEARCH ARTICLE

\title{
Influence of High Density Planting under Modified System of Rice Intensification on Growth, Root Characteristics and Yield of Rice in the Western zone of Tamil Nadu
}

\author{
Sandra Maria Saju* and Thavaprakaash N \\ Department of Agronomy, Tamil Nadu Agricultural University, Coimbatore - 641003.
}

\begin{abstract}
A field experiment was conducted during the late Samba (SeptemberJanuary) season of 2018-19 to evaluate the growth, root characters, and yield of rice due to high-density planting. The soil of the experimental field was clay loam in texture with a neutral reaction. The experiment consisted of eight treatments with different spacing and fertilizer levels such as $\mathrm{T}_{1}-25 \mathrm{~cm} \times 25 \mathrm{~cm}$ with $100 \%$ Recommended Dose of Fertilizers (RDF), $\mathrm{T}_{2}-25 \mathrm{~cm} \times 20 \mathrm{~cm}$ with $100 \% \mathrm{RDF}, \mathrm{T}_{3}-25 \mathrm{~cm} \times 15 \mathrm{~cm}$ with $100 \% \mathrm{RDF}$, $\mathrm{T}_{4}-25 \mathrm{~cm} \times 15 \mathrm{~cm}$ with $125 \% \mathrm{RDF}, \mathrm{T}_{5}-20 \mathrm{~cm} \times 20 \mathrm{~cm}$ with $100 \% \mathrm{RDF}, \mathrm{T}_{6}-$ $20 \mathrm{~cm} \times 15 \mathrm{~cm}$ with $100 \% \mathrm{RDF}, \mathrm{T}_{7}-20 \mathrm{~cm} \times 15 \mathrm{~cm}$ with $125 \% \mathrm{RDF}$ and $\mathrm{T}_{8}$ - Conventional cultivation (20 cm x 10cm with $100 \%$ RDF) and replicated thrice. The results revealed that significantly taller plants were recorded with all SRI treatments $\left(T_{1}\right.$ to $\left.T_{7}\right)$ compared to conventional planting in all the stages except at maturity, which resulted in non-significant results. A reverse trend was noted with leaf area index and straw yield. Root length and root volume of rice were higher in wider planted treatments $\left(T_{1}, T_{2}\right.$, and $\left.T_{5}\right)$ than other closer spaced treatments with the least in $T_{8}$. Treatments $T_{5}, T_{4}$ and $\mathrm{T}_{3}$ produced significantly higher grain yield over other treatments with the minimum in $\mathrm{T}_{8}$. The results inferred that too wider and too closer spacing levels under the SRI method would lead to a reduction in yield though other growth parameters were recorded more.
\end{abstract} Received : $30^{\text {th }}$ December, 2019 Revised : $10^{\text {th }}$ February, 2020 Revised : $27^{\text {th }}$ February, 2020 Accepted : $11^{\text {th }}$ March, 2020

Keywords: Rice, modified SRI, plant height, LAI, root characteristics, yield.

\section{INTRODUCTION}

Rice crop yield is determined mainly by temperature, solar radiation, moisture, and soil fertility. Sparse crop stand utilizes these resources less; whereas, the dense population may limit the availability of these factors. Maintaining optimum crop stand through proper planting methods found to increase the productivity of rice (Ghosh and Sharma, 1997). Presently, India has the largest area (43.5 mha) under rice (Indiastat, 2018) among all the countries across the globe with a production of 110 $\mathrm{mt}$ while the average rice productivity of the country is far below the global average (3.76 t.ha-1) (NRRI, 2018). With the increasing demand for rice and scarcity of water and land resources, there exists a demand for higher productivity of rice to satisfy the world's rising food needs.

The system of rice intensification (SRI) can be a better, efficient, and resource-saving approach in rice farming under rainfed and irrigated conditions. $\mathrm{SRI}$ is involved with changes in management practices, which render better growing conditions for rice plants, compared to traditional practices. In India, SRI has a potential area of 13.5 mha, which is 31 per cent of the total rice area (Mittal and Sharma, 2018). Currently, all over India, 25 x $25 \mathrm{~cm}$ spacing, is recommended in the SRI method. The loss of a few plants or poor tillering may cause yield losses. To address the issue, high-density planting using SRI principles is one option that ensures the required tillers/unit area and, in turn, the yield of rice. With high-density planting, a higher population compensates for the loss in rice yield due to the greater number of plants and tiller population/unit land area (Das et al., 1988). Hence, the present study was conducted to investigate the effect of high-density planting on growth, root characteristics, and yield of rice.

\section{MATERIAL AND METHODS}

\section{Location}

A field experiment was conducted at the Wetland farms of Tamil Nadu Agricultural University, Coimbatore $\left(11^{\circ} 02^{\prime} \mathrm{N}\right.$ latitude and 76³ $\mathrm{E}$ 
longitude, with an altitude of $426.7 \mathrm{~m}$ above MSL and receives a mean annual rainfall of $731 \mathrm{~mm}$ over 48 rainy days) during late Samba (SeptemberJanuary) season, 2018-19 on clay-loamy soil. The soil was low in available $\mathrm{N}\left(226.8 \mathrm{~kg} \mathrm{ha}^{-1}\right)$, medium in available $\mathrm{P}\left(19.25 \mathrm{~kg} \mathrm{ha}^{-1}\right)$, and high in available K (571.1 kg ha-1). Rice variety CO 52, with a duration of 130-135 days and an average yield of $6191 \mathrm{~kg} \mathrm{ha}^{-1}$ was used for the study.

\section{Field experimentation}

The experiment consisted of eight treatments with three replications and was laid out in Randomized Completely Block Design (RCBD). The treatments comprised of $\mathrm{T}_{1}-25 \mathrm{~cm} \times 25 \mathrm{~cm}$ with $100 \%$ Recommended Dose of Fertilizers (RDF), $\mathrm{T}_{2}-25 \mathrm{~cm} \mathrm{x}$ $20 \mathrm{~cm}$ with $100 \% \mathrm{RDF}, \mathrm{T}_{3}-25 \mathrm{~cm} \times 15 \mathrm{~cm}$ with $100 \%$ $\mathrm{RDF}, \mathrm{T}_{4}-25 \mathrm{~cm} \times 15 \mathrm{~cm}$ with $125 \% \mathrm{RDF}, \mathrm{T}_{5}-20 \mathrm{~cm}$ x $20 \mathrm{~cm}$ with $100 \%$ RDF, $\mathrm{T}_{6}-20 \mathrm{~cm} \times 15 \mathrm{~cm}$ with $100 \% \mathrm{RDF}, \mathrm{T}_{7}-20 \mathrm{~cm} \times 15 \mathrm{~cm}$ with $125 \% \mathrm{RDF}$ and $\mathrm{T}_{8}$ - Conventional cultivation (transplanting 25-30 days old seedlings at $20 \mathrm{~cm} \times 10 \mathrm{~cm}, 2-3$ seedlings. hill $^{-1}$ ) with $100 \%$ RDF. SRI principles were practiced for treatments $T_{1}$ to $T_{7}$.

The recommended fertilizer dose for medium duration variety was 150:50:50 kg N: $\mathrm{P}_{2} \mathrm{O}_{5}: \mathrm{K}_{2} \mathrm{O}$ $\mathrm{kg} \mathrm{ha}^{-1}$ which was applied through urea $(46 \% \mathrm{~N})$, single superphosphate $\left(16 \% \mathrm{P}_{2} \mathrm{O}_{5}\right)$ and muriate of potash $\left(60 \% \mathrm{~K}_{2} \mathrm{O}\right)$. Full dose of phosphorus was applied as basal. Nitrogen and potassium were given in four equal split doses i.e., at basal, active tillering (50 DAT), panicle initiation (70 DAT), and flowering stages (100 DAT). All the other cultural operations were carried out as per CPG (2012).

\section{Observations}

Five hills were tagged randomly within the net plot and plant height and leaf area index at different stages of crop growth viz., active tillering, panicle initiation, flowering and maturity stages, were recorded. The plant height was measured from ground level to the tip of the longest leaf at active tillering and panicle initiation stages and up to the tip of panicle at flowering and maturity stages, and the mean value was expressed in centimetre. Leaf area index (LAl) was calculated as suggested by Palanisamy and Gomez (1974). The number of days taken to attain 50 per cent flowering and the number of days to physiological maturity from the date of sowing were recorded for each plot and expressed in days.

Five plants randomly selected from the sampling area and were uprooted at active tillering, panicle initiation and flowering stages. The roots were washed carefully, and the length of the root measured till the tip and was expressed in centimetre. The same roots were used to measure the root volume by displacement method using a measuring cylinder and were expressed in cc hill-1. Harvested plants from the net plot area were threshed, cleaned, dried and weighed to moisture content of 14 per cent and the grain and straw weight were expressed in $\mathrm{kg} \mathrm{ha}^{-1}$. The data were subjected to statistical scrutiny at 5 per cent level of significance (Gomez and Gomez, 2010).

\section{RESULTS AND DISCUSSION}

\section{Growth characters}

There was a steady increase in plant height up to the flowering stage and declined thereafter (Table 1). At the active tillering stage, significantly higher plant height $(59.4 \mathrm{~cm})$ was recorded at a plant spacing of $25 \mathrm{~cm} \times 15 \mathrm{~cm}$ fertilized with $125 \%$ RDF $\left(\mathrm{T}_{4}\right)$, which was statistically on par with all other treatments except control $(20 \mathrm{~cm} \times 10 \mathrm{~cm}$ with $100 \%$ RDF). Taller and non-significant results were noted in $T_{1}$ to $T_{7}$ treatments and shorter plants in $T_{8}$ at panicle initiation and flowering stages too. Plant height at maturity stage was found statistically on par with all treatments. Shorter plants at the conventional system of planting than other treatment levels at three initial growth stages could be attributed to the late transplanting of the crop (30 DAS), which in turn led to slower growth.

Table 1. Effect of high-density planting on the growth of rice under the modified system of rice intensification

\begin{tabular}{|c|c|c|c|c|c|c|c|c|c|c|}
\hline \multirow{2}{*}{ Treatments } & \multicolumn{4}{|c|}{ Plant height $(\mathrm{cm})$} & \multicolumn{4}{|c|}{ Leaf area index } & \multirow{2}{*}{$\begin{array}{l}\text { Days to } \\
\text { flowering }\end{array}$} & \multirow{2}{*}{$\begin{array}{l}\text { Days to } \\
\text { maturity }\end{array}$} \\
\hline & AT & PI & $\mathrm{FL}$ & MT & AT & $\mathrm{PI}$ & $\mathrm{FL}$ & MT & & \\
\hline T1: $25 \times 25 \mathrm{~cm}+100 \%$ RDF & 59.1 & 84.7 & 112.5 & 106.7 & 1.60 & 4.60 & 3.97 & 1.89 & 92.0 & 122.0 \\
\hline T2: $25 \times 20 \mathrm{~cm}+100 \%$ RDF & 58.1 & 86.4 & 114.7 & 111.0 & 2.17 & 5.30 & 4.43 & 2.10 & 92.0 & 122.0 \\
\hline T3: $25 \times 15 \mathrm{~cm}+100 \%$ RDF & 58.4 & 82.7 & 113.2 & 104.8 & 2.50 & 5.60 & 4.67 & 2.40 & 92.0 & 122.0 \\
\hline T4: $25 \times 15 \mathrm{~cm}+125 \%$ RDF & 59.4 & 86.0 & 109.2 & 105.0 & 2.57 & 5.77 & 4.70 & 2.51 & 93.2 & 123.5 \\
\hline T5: $20 \times 20 \mathrm{~cm}+100 \%$ RDF & 58.4 & 85.6 & 113.0 & 109.1 & 2.40 & 5.57 & 4.63 & 2.31 & 92.0 & 122.0 \\
\hline T6: $20 \times 15 \mathrm{~cm}+100 \%$ RDF & 55.7 & 87.5 & 113.8 & 107.3 & 2.97 & 6.73 & 5.50 & 2.91 & 91.6 & 122.0 \\
\hline T7: $20 \times 15 \mathrm{~cm}+125 \%$ RDF & 58.2 & 85.7 & 111.2 & 105.2 & 2.77 & 6.53 & 5.30 & 2.70 & 93.1 & 123.6 \\
\hline T8: $20 \times 10 \mathrm{~cm}+100 \%$ RDF & 48.8 & 78.2 & 104.1 & 105.3 & 2.47 & 7.17 & 5.82 & 3.40 & 96.4 & 127.0 \\
\hline SEd & 2.5 & 2.2 & 2.9 & 6.2 & 0.11 & 0.31 & 0.29 & 0.12 & 3.8 & 5.1 \\
\hline$C D(P=0.05)$ & 4.1 & 4.8 & 6.2 & NS & 0.24 & 0.67 & 0.64 & 0.27 & NS & NS \\
\hline
\end{tabular}

AT - Active tillering stage; PI - Panicle initiation stage; FL - Flowering stage; MT - Maturity stage; NS - Non-significant

Seedlings transplanted at a young age ( $<15$ days $)$ under SRI had a more significant time to acclimatize to field conditions which consequently resulted in increased plant height (Kesh et al., 2017). Non-

$107|1-3| 26$ 
significant plant height at maturity stage indicated that being a genetically made characteristic of the individual rice variety, it would not vary with the change of spacing and fertilizer levels at the end of its life cycle.

The computed mean data on the leaf area index of rice at different growth stages indicated an increase in LAl during active tillering to panicle initiation stages followed by a declining trend up to maturity stage (Table 1). At the active tillering stage, a significantly higher LAI (2.97) was recorded under $20 \mathrm{~cm} \times 15 \mathrm{~cm}$ plant spacing at $100 \% \operatorname{RDF}\left(\mathrm{T}_{6}\right)$ than other treatments, but with $20 \mathrm{~cm} \times 15 \mathrm{~cm}$ spacing applied with $100 \%$ RDF $\left(T_{7}\right)$. The planting pattern of $25 \mathrm{~cm} \times 25 \mathrm{~cm}$ with $100 \% \operatorname{RDF}\left(\mathrm{T}_{1}\right)$ recorded a lower LAl (1.60) compared to all other treatments. Conventional planting $\left(\mathrm{T}_{8}\right)$ recorded a perceptibly higher LAI (7.17, 5.82, and 3.40) at panicle initiation, flowering, and maturity stages, respectively, compared to all other treatments. It was statistically identical to plant spacing of $20 \times 15 \mathrm{~cm}$ at $100 \%$ and $125 \% \operatorname{RDF}\left(\mathrm{T}_{6}\right.$ and $\mathrm{T}_{7}$ ) at panicle initiation and flowering stages. Wider plant spacing of $25 \times 25 \mathrm{~cm}$ applied with $100 \%$ RDF $\left(T_{1}\right)$ registered significantly lower LAl at panicle initiation (4.60), flowering (3.97), and maturity (1.89) stages over other treatments. Generally, the leaf area index depends on the number of tillers/hill, the number of green leaves, and leaf area. Significantly higher LAI was observed under the conventional method of planting while lower LAl was recorded when spacing was increased and the least was noticed in the widest spacing level tested $(25 \times 25 \mathrm{~cm})$. Our findings are parallel with the results reported by Rajput et al. (2016). Higher LAI at closer spacing was due to the increase in number of tillers and hence, more number of leaves in a unit area without much variation in leaf breadth when compared to wider spacing levels. Despite a superior plant stature under wider spacing, it did not compensate for the collective leaf area due to reduced number of leaves.

Table 2. Effect of high-density planting on root characters of rice under the modified system of rice intensification

\begin{tabular}{|c|c|c|c|c|c|c|}
\hline \multirow{2}{*}{ Treatments } & \multicolumn{3}{|c|}{ Root length (cm) } & \multicolumn{3}{|c|}{ Root volume (cc/hill) } \\
\hline & AT & PI & FL & AT & PI & $\mathrm{FL}$ \\
\hline $\mathrm{T}_{1}: 25 \times 25 \mathrm{~cm}+100 \% \mathrm{RDF}$ & 29.20 & 30.12 & 31.49 & 29.7 & 43.7 & 136.0 \\
\hline $\mathrm{T}_{2}: 25 \times 20 \mathrm{~cm}+100 \% \mathrm{RDF}$ & 27.43 & 29.50 & 30.69 & 28.3 & 41.7 & 116.7 \\
\hline $\mathrm{T}_{3}: 25 \times 15 \mathrm{~cm}+100 \% \mathrm{RDF}$ & 26.96 & 27.28 & 29.52 & 21.7 & 36.3 & 101.1 \\
\hline $\mathrm{T}_{4}: 25 \times 15 \mathrm{~cm}+125 \% \mathrm{RDF}$ & 26.32 & 27.04 & 29.16 & 21.0 & 34.0 & 93.3 \\
\hline $\mathrm{T}_{5}: 20 \times 20 \mathrm{~cm}+100 \% \mathrm{RDF}$ & 27.00 & 29.17 & 30.32 & 27.3 & 40.7 & 108.6 \\
\hline $\mathrm{T}_{6}: 20 \times 15 \mathrm{~cm}+100 \% \mathrm{RDF}$ & 24.64 & 26.08 & 27.05 & 19.7 & 33.3 & 91.0 \\
\hline $\mathrm{T}_{7}: 20 \times 15 \mathrm{~cm}+125 \% \mathrm{RDF}$ & 24.09 & 25.69 & 26.28 & 17.7 & 32.3 & 89.7 \\
\hline $\mathrm{T}_{8}: 20 \times 10 \mathrm{~cm}+100 \% \mathrm{RDF}$ & 21.50 & 22.45 & 24.53 & 10.7 & 20.0 & 80.5 \\
\hline SEd & 1.40 & 1.01 & 0.80 & 1.4 & 1.2 & 5.5 \\
\hline $\mathrm{CD}(\mathrm{P}=0.05)$ & 2.90 & 2.20 & 1.60 & 3.1 & 2.6 & 11.7 \\
\hline
\end{tabular}

AT - Active tillering stage $\quad \mathrm{Pl}$ - Panicle initiation stage

Days to flowering and days to maturity did not vary significantly due to spacing and fertilizer levels imposed during the study (Table 1) since they are genetic characteristics of the variety, which would not vary with different treatments applied in the study.

\section{Root length and root volume}

Root length and root volume are important parameters that reflect the crop growth. There existed variation in the root length of rice due to different spacing levels along with fertilizer doses imposed during the study (Table 2). At active tillering stage, significantly higher root length $(29.20 \mathrm{~cm})$ was recorded under $25 \times 25 \mathrm{~cm}$ fertilized with $100 \%$ $\mathrm{RDF}\left(\mathrm{T}_{1}\right)$ than all other treatments except $25 \times 20 \mathrm{~cm}$ $(27.43 \mathrm{~cm}), 20 \times 20 \mathrm{~cm}(27.00 \mathrm{~cm})$ and $25 \times 15 \mathrm{~cm}$ $(26.96 \mathrm{~cm}$ ) all applied with 100\% RDF and $25 \mathrm{x}$ $15 \mathrm{~cm}$ with $125 \%$ RDF $(26.32 \mathrm{~cm})$. Shorter roots $(21.50 \mathrm{~cm})$ were measured under closer planting of $20 \times 10 \mathrm{~cm}$ with $100 \% \operatorname{RDF}\left(\mathrm{T}_{8}\right)$, which was statistically identical to $20 \times 15 \mathrm{~cm}$ with $125 \%$ RDF $\left(\mathrm{T}_{7}\right)$. At panicle initiation and flowering stages also,
$\mathrm{FL}$ - Flowering stage

significantly longer roots were noted in the same $T_{1}$ treatment $(25 \mathrm{~cm} \times 25 \mathrm{~cm}$ with $100 \% \mathrm{RDF})$ as like active tillering stage compared to other treatments. However, it maintained statistical parity with $25 \mathrm{~cm} \mathrm{x}$ $20 \mathrm{~cm}$ with $100 \% \operatorname{RDF}\left(\mathrm{T}_{2}\right), 20 \mathrm{~cm} \times 20 \mathrm{~cm}$ with $100 \%$ $\operatorname{RDF}\left(T_{5}\right)$ and $25 \mathrm{~cm} \times 15 \mathrm{~cm}$ with $100 \% \operatorname{RDF}\left(T_{3}\right)$. Shorter roots were produced under the conventional method of planting $\left(\mathrm{T}_{8}\right)$.

Irrespective of growth stages, planting geometry of $25 \mathrm{~cm} \times 25 \mathrm{~cm}$ applied with $100 \% \operatorname{RDF}\left(\mathrm{T}_{1}\right)$ recorded a distinctly more root volume compared to all other spacing levels. At the active tillering stage, rice planted at $25 \mathrm{~cm} \times 25 \mathrm{~cm}$ spacing level and fertilized with $100 \% \operatorname{RDF}\left(T_{1}\right)$ produced copious roots by volume $(29.7 \mathrm{cc} /$ hill) than other treatments but was statistically on par with $25 \mathrm{~cm} \times 20 \mathrm{~cm}\left(\mathrm{~T}_{2}\right)$ and $20 \mathrm{~cm} \times 20 \mathrm{~cm}\left(\mathrm{~T}_{5}\right)$ both received $100 \%$ RDF. Significantly lower root volume $(10.7 \mathrm{cc} / \mathrm{hill})$ was obtained at a closer plant spacing of $20 \mathrm{~cm} \times 10 \mathrm{~cm}$ with $100 \% \operatorname{RDF}\left(T_{8}\right)$. Similar results were obtained at panicle initiation and flowering stages also. 
Under wider crop geometry, there is reduced competition for resources like nutrient, water, light, air and evidently improved the growth of individual plant (Thakur and Uphoff, 2010). Better root characteristics under SRI might be due to the effect of transplanting of young and single seedling/hill combined with suitable irrigation management practices and better soil aeration by the usage of rotary weeder. Also, there was no transplanting trauma due to the transplanting of younger seedlings, which facilitated the quicker establishment of the crop in the field. The availability of increased spacing for individual plants improved the foraging capacity by the horizontal spread of roots that in turn, increased the root length and root volume. These congenial growth conditions under SRI method allowed the crop to complete more number of phyllochrons, generating increased tillers and roots, before the flowering phase (Hidayati and Anas, 2016). The findings are in close vicinity with the findings of Chapagain and Yamaji (2010), Mishra and Salokhe (2010) and Bhavya et al. (2018). Under the conventional system, cultural practices of transplanting of older seedlings at 3-4 seedlings/ hill, continuous flooding of the field throughout crop would have resulted in poor root growth with quicker root degeneration.

\section{Grain and straw yields}

Distinct variation in grain yield of rice was observed due to the adoption of different spacings and fertilizer doses in the present study (Figure 1). Significantly higher grain yield $\left(6392 \mathrm{~kg} \mathrm{ha}^{-1}\right)$ was obtained under spacing of $20 \mathrm{~cm} \times 20 \mathrm{~cm}$ with $100 \%$ RDF $\left(T_{5}\right)$, where an increase in grain yield of 26.3 per cent was realized over the conventional system $\left(\mathrm{T}_{8}\right)$ and 12.8 per cent over SRI method $\left(\mathrm{T}_{1}\right)$. However, it was very much comparable to the yield recorded at $25 \mathrm{~cm} \times 15 \mathrm{~cm}$ fertilized with 125\% RDF ( $\mathrm{T}_{4}-6272$ $\left.\mathrm{kg} \mathrm{ha}^{-1}\right), 25 \mathrm{~cm} \times 20 \mathrm{~cm}$ with 100\% RDF ( $\mathrm{T}_{2}-6259$ $\left.\mathrm{kg} \mathrm{ha}^{-1}\right)$ and $25 \mathrm{~cm} \times 15 \mathrm{~cm}$ with 100\% RDF ( $\mathrm{T}_{3}-5951$ kg ha-1). Wider planting under SRI (5667 kg ha-1) stood next in order. An increase in grain yield of 12.4 per cent, 10.4 per cent and 5.04 per cent, respectively due to $T_{4}, T_{2}$, and $T_{3}$ was recorded over the SRI method $\left(T_{1}\right)$ being currently practised. The conventional system of planting had recorded significantly lower grain yield (5061 kg ha-1) over other treatments. It was statistically on par with planting geometry of $20 \mathrm{~cm} \times 15 \mathrm{~cm}$ with either $100 \%$ RDF (5163 kg ha-1) or 125\% RDF (5193 kg $\left.\mathrm{ha}^{-1}\right)$. Higher yield under these treatments can be attributed to the optimum plant population and better yield attributes recorded from the treatment such as the number of productive tillers, total grains/ panicle, and filled grains/panicle. In addition, fairly better performance of root characteristics resulted in improved nutrient foraging and dry-matter accumulation, which in turn paved the way for better yield attributes. Similar results reported by Baskar et al. (2013). Lower grain yield was also recorded under closer spacing by Jahan et al. (2017). Thavaprakaash et al. (2017) also reported an increased grain yield at the optimum spacing level and reduced yield under too closely and wider spacing levels in rice under the SRI method.

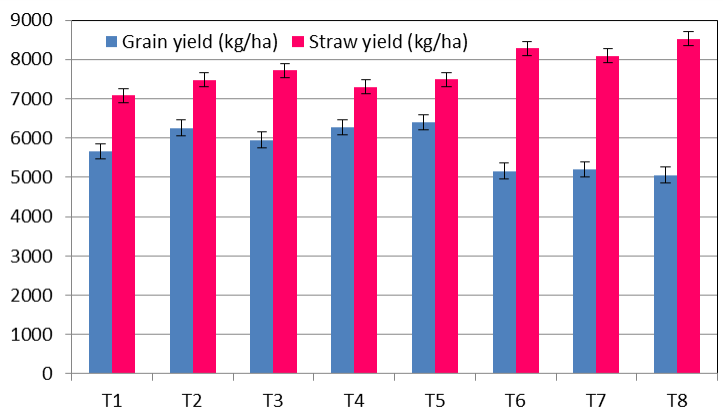

Figure 1. Effect of high density on yield of rice

Spacings adopted and fertilizer doses applied in the study had a profound influence on the straw yield of rice. Significantly higher straw yield $(8523 \mathrm{~kg}$ $\left.\mathrm{ha}^{-1}\right)$ at harvest was recorded under the conventional system of planting $\left(T_{8}\right)$, and it was 20.3 per cent higher than the straw yield obtained from SRI. However, it was statistically identical to $20 \mathrm{~cm} \mathrm{x}$ $15 \mathrm{~cm}$ with either $100 \% \operatorname{RDF}\left(8278 \mathrm{~kg} \mathrm{ha}^{-1}\right)$ or $125 \%$ RDF (8090 kg ha-1). Significantly lower straw yield (7084 kg ha-1) was obtained under the SRI method of planting $\left(T_{1}\right)$. But, the treatment $T_{1}$ was statistically on par with $25 \mathrm{~cm} \times 20 \mathrm{~cm}$ with $100 \%$ RDF $(7478 \mathrm{~kg}$ $\left.\mathrm{ha}^{-1}\right), 20 \mathrm{~cm} \times 20 \mathrm{~cm}$ with $100 \% \operatorname{RDF}\left(7484 \mathrm{~kg} \mathrm{ha}^{-1}\right)$, $25 \mathrm{~cm} \times 15 \mathrm{~cm}$ with $125 \% \operatorname{RDF}\left(7300 \mathrm{~kg} \mathrm{ha}^{-1}\right)$ and $25 \mathrm{~cm} \times 15 \mathrm{~cm}\left(7725 \mathrm{~kg} \mathrm{ha}^{-1}\right)$ applied with 100\% RDF. Higher straw yield can be ascribed to a higher number of tillers $/ \mathrm{m}^{2}$ without altering the number of leaves, increased leaf area index, and better dry- matter production recorded under in conventional method of planting. Improved nutrient uptake, together with the delay in leaf senescence, led to more photosynthesis during later crop growth stages resulting in higher straw yield. Similar result was recorded by Thavaprakaash et al. (2017).

\section{CONCLUSION}

From the experimental results, it could be concluded that plants were taller at different growth stages while practising $S R I\left(T_{1}\right.$ to $\left.T_{7}\right)$ when compared to the conventional method, whereas, the results were reverse with LAI and straw yield. Root characters such as root length and root volume were also higher in SRI method $\left(T_{1}\right)$ compared to all spacing and fertilizer treatments studied in the experiment. However, plant spacing of $20 \mathrm{~cm} \times 20 \mathrm{~cm}$ with $100 \%$ RDF and row spacing of $25 \mathrm{~cm}$ with a plant spacing of $20 \mathrm{~cm}$ and $15 \mathrm{~cm}$ applied with $100 \%$ and $125 \%$ RDF out performed other treatments in terms 
of grain yield. Hence, it is concluded that though the growth characters behaved differently, the grain yield was higher at a plant density of $2,00,000$ to $2,66,000$ plants ha-1.

\section{REFERENCES}

Baskar, P., K. Siddeswaran, and N. Thavaprakaash. 2013. Tiller dynamics, light interception and yield of rice cultivars under system of rice intensification (SRI) as influenced by nursery techniques and spacing. Madras Agric. J., 100(1-3): 131-134.

Bhavya, M., D. Kumar, and G. Girijesh. 2018. Root growth and tillering behavior of rice as influenced by systems of establishment. Int. J. Agric. Sci., 10 (6): 5531-5535.

Chapagain, T. and E. Yamaji. 2010. The effects of irrigation method, age of seedling and spacing on crop performance, productivity and water-wise rice production in Japan. Paddy Water Environ., 8(1): 81-90.

CPG. 2012. Crop Production Guide. Department of Agriculture, Govt. of Tamil Nadu, Chennai and Tamil Nadu Agricultural University, Coimbatore.

Das, K., D. Biswal and T. Pradhan. 1988. Effect of plant density and age of seedlings on the growth and yield of rice variety Parijat. Oryza ,25: 191-194.

Ghosh, A. and A.R. Sharma. 1997. Effect of seed rates, seed density and nitrogen on performance of flood prone low land rice. Int. Rice Res. Notes (Philippines) 22: 37-38.

Gomez, K.A. and A.A. Gomez. 2010. Statistical procedures for agricultural research Vol. $2^{\text {nd }} \mathrm{Ed}$., Wiley India Pvt Ltd., New Delhi.

Hidayati, N. and I. Anas. 2016. Photosynthesis and transpiration rates of rice cultivated under the system of rice intensification and the effects on growth and yield. HAYATI J. Biosci., 23(2): 67-72.

Indiastat. 2018. "www.indiastat.com".

Kesh, H., K. Ram, and K. Jangid. 2017. System of rice intensification: A review on resource conserving method of rice crop establishment. Int. J. Cur. Microbiol. Applied Sci., 6(11): 2315-2328.
Jahan, S., M. A. R. Sarkar, and S. K. Paul. 2017. Effect of plant spacing and fertilizer management on the yield performance of BRRI dhan 39 under Old Brahmaputra Floodplain Soil. Madras Agric. J., 104 (1-3): 37-40.

Mishra, A. and V. Salokhe. 2010. Flooding stress: The effects of planting pattern and water regime on root morphology, physiology and grain yield of rice. $J$. Agron. Crop Sci., 196(5): 368-378.

Mittal, S. and S.K. Sharma. 2018. Effect of different approaches of fertilizer recommendations on yield, nutrient uptake and economics of rice under SRI. $J$. Pharmacogn. Phytochem., 7(2): 761-765.

NRRI. 2018. Annual Report 2017-18. Cuttack: ICARNRRI.

Palanisamy, K.M. and K.A. Gomez. 1974. Length, width method for estimating leaf area for rice. Agron. J., 66: 430-433.

Rajput, A., S.S. Rajput and G. Jha. 2016. Performance of rice varieties grown under different spacings with planting depths in system of rice intensification. Int. J. Agric. Environ. Biotech., 9(5): 833-838.

Thakur, A. and N. Uphoff. 2010 An assessment of physiological effects of system of rice intensification (SRI) practices compared with recommended rice cultivation practices in India. Experimental Agric., 46(1): 77-98.

Thavaprakaash, N., P. Baskar and A. Velayutham. 2017. Influence of planting geometry on growth and yield of rice (Oryza sativa L.) under SRI practices. The Bioscan. 12(1): 557-560.

Yamah, A., 2002. The practice of the system of rice intensification in Sierra Leone. In Uphoff $\mathrm{N}$, Fernandes E, Long-Pin $\mathrm{Y}$, Jiming $\mathrm{P}$, Sebastien R, Rabenanadrasana J, editors. Assessments of the System of Rice Intensification (SRI): Proceedings of an international conference, Sanya, China, 1- 4 April 2002, Ithaca, NY(USA): CIIFAD, pp 23-25 Zhao, 